patient is literally starred to death and in a comparatively unfarourable state for recorery. If under these unpromising conditions recovery habitually occurs, how much more sanguine may we be in earlier cases where there still remains some reserve of strength.

I have lately operated (July, 1896), by gastro-jejunostomy, on another case having symptoms of duodenal ulceration, with great relief.

Leicester.

\section{A NEW FORM OF TRACHEAL VALVE.}

\section{By PHILIP DE SANTI, F.R.C.S. ENG.,}

ASSISTANT SLRGEON, AURAL SERGEON, AXD LECTURFR ON ATRAL SI RGERY TO WESTMIXSTER HOSPITAL.

IT is the experience of every medical man to occasionally come across cases where a patient has to wear for some months or permanently a tracheotomy tube. In such cases when the patient attempts to talk he has to place his finger on the mouth of the tube, and this naturally is a source of considerable inconvenience; again, on coughing the expectoration is voided through the tracheotomy tube, a most uncleanly and unpleasant condition of affairs for the wearer of the tube. In order to overcome these difficulties one or two forms of tracheal valves bare been invented. The first was that of Luer, who introduced the " pea valve" consisting of a small chamber containing a small ball and fitting into the mouth of the cannula. When the patient speaks the pea is forced forwards and blocks up the anterior opening, whilst on inspiration it falls backwards into the cavity of the chamber and allows the air to enter the trachea. This pea valve has, however, in my experience, the following disadvantages: (1) the movements of the "pea" are noisy and therefore cause annoyance to the patient; (2) the ball very readily gets clogged with mucus, \&c., and is very difficult to clean and keep clean; and (3) it often gets out of order. To obviate the "rattling" noises of the pea Mr. Thomas Smith invented a valre consisting of a little silver box with an indiarubber flap permitting inspiration but closing on expiration and vocalisation. The disadvantages of this valve are: (1) the impossibility of keeping the indiarubber flap clean; and (2) the tendency of the valve to become soft and sodden and to be forcibly coughed out. To prevent this tendency of the valve to be coughed out a small, fine central crossbar has been made, but even with this the tendency to "herniation" of the indiarubber valve is great. Having during the last two years harl under my care a patient who has wurn and is oblioed to wear a tracheotomy tube permanently for a condition of larynx in which inspiration is greatly impeded but expiration casy, I have had occasion to try the Luer "pea valve" and Mr. Smith's valve. Both have, however, been unsatisfactory, the patient having to discontinue them as practically useless. I therefore determined to try to invent a valve myself, and after several attempts finally produced the one illustrated here. My patient, a man who travels a great deal abroad and who is fond of a social life, has found the greatest annoyance and discomfort from the expulsion of mucus, \&c., from his tracheotomy tube and the irability to speak without placing his finger on the tube. He therefore tried the two abovementioned valves, but, as I have said, had to discard them. He then ased my valve, and has now worn it for some nine months with eminently satisfactory results. He is able to wear an ordinary shirt and high collar, to expectorate or cough naturally through the mouth, and to breathe and talk quite freely and without exertion. During the last six or seren months be has taken to bicycling regularly and can travel bis twenty to thirty miles a day withont any inconvenience.

Fig. 1 shows the tracheotomy tube and ralve fitted together, the chamber and valre by itself and a section of the chamber and ralre showing its construction and mode of action. The ralce apparatus consists of a small silrer chamber, $A$, about half an inch lorg fitting accurately into the cannula, B, and open at both ends. Inside this chamber is a small, circular, silver valre working on a binge. which on inspiration is drawn inwards against the calibre of the chamber, thus permitting of free ingress of air, and which on expiration, vocalisation, or coughing is driven

forwards and comes up tightly against a small silver inner rim, thereby preventing any exit of air, mucus, \&c. Great care must be taken to make this valve air-tight. In case by any chance, which is remote, this small silver valve should get loose and fall into the trachea, I have had another small silver rim made at the distal end of the silver chamber. This accident is therefore rendered impossible. The edge of the silver chamber is milled so that it can easily be put in or taken out with the fingers, and the upper central part of the valve is indicated by a small notch indicating

FIG. 1.

B

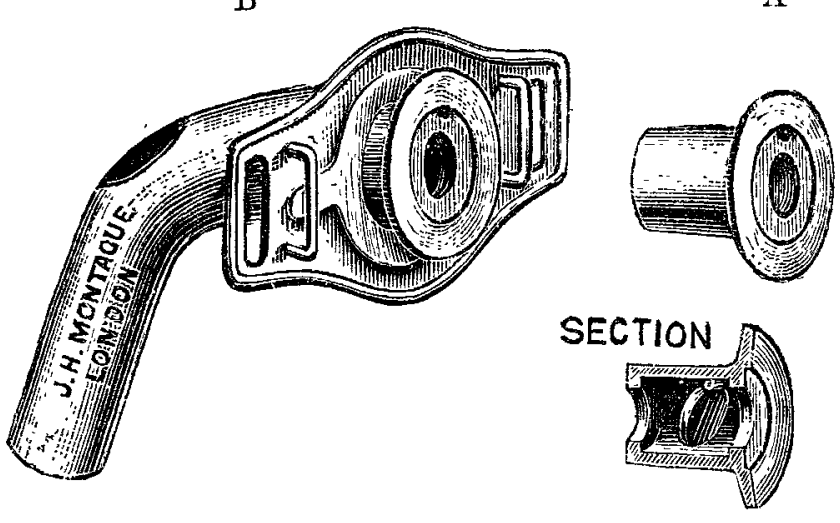

the position in which the valve should hang. The advantages I claim for this valve are: (1) its simplicity; (2) the facility with which it can be sterilised and kept clean (my patient has two valves and when one gets dirty he simply boils it in a solution of bicarbonate of soda, dries it, and it is then ready for use); (3) the working of the valve is unaccompanied by any "rattling" noises ; (4) the valve is air-tight and cannot be coughed out being made of silver; and (5) the supply of air is but little diminished, considerably less so than in Luer's or Smith's valves. (In the diagrams the aperture of entry in Fig. 1, A and B, is drawn too small. The upper and lower rims in the sectional figure are too wide.) The cannula into which the valve and its chamber fit has an opening on its upper convex side to permit of the expired air passing through the larynx, or the cannula may be of the skeleton variety (Fig. 2) which I have invented for

FIG. 2.

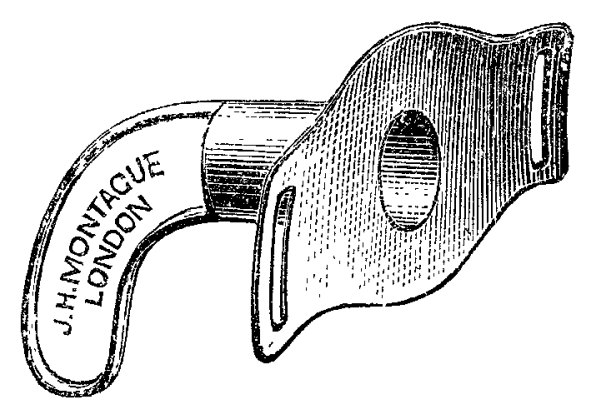

my patient in order to give him as much breathing space as possible and which he wears with much comfort. The valves are made for me by Mr. J. H. Montague, of 101, New Bond-street, W.

Harley-street, $\mathbf{W}$

UNDULANT (MALTA) FEVER.

BY SURGEON-CAPTAIN M. LOUIS HUGHES, ARMY MEDICAL STAFF, MALTA.

Synonyms.-The following synonyms have been used:Mediterranean gastric remittent fever (Marston, 1861 Boileau, 1865; Chartres, 1866) ; remittent fever (Official Returns of the Royal Navy and Civil Government of Malta); 1a febbre gastro-biliosa (Guilia, 1871); febris sudoralis (Tomasselli, 1880); febbre miliare (Frederici, 1885, \&c.) febris complicata (Veale, 1879); intermittent typhoid ferer (Borrelli, 1887); adeno-tifo (Cantani, 1878); febricola typhosa (De Renzi, 1884); febbre typhoidea atipica (Capozzi, 1885) ileo-tifo a forma sudcrale (Jaccoud, 1885-6); pseudo-tifo (Guiffre, 1893); typho-malarial fever (Maclean, 1875-85, \&c.); 
fæco-malarial fever (Donaldson, 1876); febbre continua epidemica (Tomaselli, 1886); simple continued fever (Military returns); Mediterranean fever (Burnett, 1810; Guiffre, $1893, \& c$.$) ; rock or Gibraltar fever (Turner, 1884$; Moffett, 1889, \&c ) ; Malta fever (Oswald, Wood, and Notter, 1876 ; Bruce, 1887, \&s.) ; Neapolitan fever (Borrelli, 1887; Galassi, 1883); febbre infettiva atipica (Rummo, 1881); pythogenic septicæmia (Moffett, 1889); febbre climatica (Pasquale, de Conciliis, 1889, \&c.) ; recurrent, country, sewage, mephitic, cesspool, town, Cretan, Cyprus, Levant, \&c., fever.

Definition.-The following is a definition of the disease. An endemic pyrexial disease, occasionally prevailing as an epidemic, having a long and indefinite duration, an irregular course, with an almost invariable tendency to undulations of pyrexial intensity, which latter condition is the most constant and characteristic feature about the disease. It is usually characterised by constipation, profuse perspirations, and frequently accompanied or followed by symptoms of a neuralgic character or by arthritic effusions. After death the spleen is found to be enlarged and often softened, many of the organs congested, but Peyer's glands are neither enlarged nor ulcerated, nor is ulceration present in any other parts of the small intestine. There is a constant presence of a definite species of micro-organism in certain tissues. ${ }^{1}$

Enough has been written and published about this fever to prove its specific and separate nature, but, unfortunately, no suitable name has been suggested by which it may be returned. Until such a name is inserted in the official nomenclature of diseases our accurate knowledge of its causation and prevention will fail to be advanced to any great or general extent, while a large amount of material for scientific investigation at the various military stations in the Mediterranean is yearly being wasted. The invention of a suitable name has proved, however, a matter of the greatest difficulty, for to come into general use the name should be so stamped with the identity of the disease as to at once recall to the mind this particular disease and no other. At the same time it must not be based on any theory which later knowledge may explode. In the returns of the Royal Nary and Maltese Civil Government all cases of this fever are described as "remittent fever," by which they come to be incluaded among the malarial group of fevers, together with all cases of paludic infection. In military returns since 1885 they have been returned, together with all cases of fever of indefinite and doubtful nature, under the heading "simple continued fever," a disease officially defined as "continuous fever having no obvious distinguishing character"! The British soldier, with unconscious punning upon the shortened term in general use (S. C. fever), has named the disease "slow continued fever," a cumbersome though not inappropriate term. Into the various combinations of the terms "typhoid, enteric, and malaria" it is unnecessary to enter; they are most unscientific and misleading. If the disease is of an enteric or malarial nature no one would hesitate to call it by one or other of these names. If, on the other hand, it is of the nature of an acute attack of enterica occurring in one already the seat of paludic infection it would be comparable to an attack of enterica or an injury affecting a syphilitic or tuberculous subject, in which case typho-syphilis or tuberculo-enteric would scarcely be considered to constitute suitable names. As, however, this fever is totally distinct from these diseases, and merely has occasional clinical resemblances, there is absolutely no excuse for such bybrid names. The term recurrent fever is descriptive, but it has too close a resemblance to the Italian "febbre ricorrente" and the German "typhus recurrens"synonyms for our relapsing fever. Geographical names have in the past been responsible for much of the confusion concerning "fevers," which for so many years retarded the progress of scientific medicine, and while they are always picked up by newcomers from the empirics of the places where these diseases exist they have never been retained after the disease has been accurately studied. No other synonym has stood the test of time, and though this question has been discussed for many years by those who have to treat cases in the places where this disease is the most common of local affections the question has still to be solved. To be perfect, a name "should be so characteristic and significant that a person but slightly acquainted with the

For further detailed information see Transactions of the Royal Medical and Chirurgical Society of London, 1896. Third Series, vol. viii., p. 176. language and subject should, on hearing it, immediately understand what is the nature of the disease it designates' (Plouquet). "It should be composed out of the same elements as the definition of the disease-in fact, it ought to be the definition converted into a name, and derived either from the symptoms of the disease or from the supposed proximate cause" (Aitken). Of its supposed proximate cause we as yet have scarcely sufficient data on which to base a name. From a clinical point of view the terms splenic or relapsing fever would have referred to definite characteristics, but both names are already in use. It has occurred to me that the term "Undulant Fever," by referring to the peculiar pyrexial curve so characteristic of the disease, might prove a serviceable name. The name appeals forcibly to the clinical observer, who, standing in a ward surrounded by cases of this fever (as anyone may do in summer in any of the military hospitals of Malta), gazes at the temperature charts on the walls and notices the way in which the recordea pyrexial curves undulate across the paper in waves of varying degree.

The advantages of the term may be briefly summarised (a) it describes the most constant and characteristic clinical feature of the disease; (b) it appears to be grammatically correct; $(c)$ it is not one that can be applied to any other febrile disease, as the terms "intermittent" and "remittent" (d) it need not be held to mean any definite quantity or amount of intensity, but as in nature undulations vary from the gentle ripple or broader swell to the chopping wave or overwhelming breaker, so may the expression be one of quality applied to the various pyrexial waves of this fever, however much they vary in length and magnitude; $(t)$ it Latin synonym (febris undulatus) renders it comprehensible to scientific men all over the civilised world, while it is easily translatable into their various individual languages, in most cases with but little change; and $(f)$ it has, moreover, a familiar sound and is easily pronounced, and as it has never been used in such connexion will not give rise to scientific ambiguity.

\section{A CASE OF CEREBRO-SPINAL MENINGITIS, COMPLICATING GONORRHCEA TREATED BY ANTIKAMNIA.}

BY G. S. LEGGATT, M.R.C.S. ENG., L.S.A.

THE following case is interesting on account of the rarity with which the cerebro-spinal dura mater is involved as a complication of gonorrhcea and as illustrating the efficacy of antikamnia in relieving the symptoms of pain and pyrexia. Antikamnia is a remedy hardly yet known in the profession, and it may be of interest to record an experience of its use.

The patient was a young man aged twenty-three years, who developed the ordinary symptoms of a first attack of gonorrhœa about March 30th, five weeks before the present illness. On May 1st he was attacked with epididymitis and kept to his bed, the urethral discharge being suppressed as usual under such circumstances. During the ensuing fire days in bed the inflammation gradually subsided and he felt very well except for some uneasiness in the back. None of the joints were involved at any time. On the morning of May 6th the dull aching pain in the back considerably increased, but there was no pyrexia. At 1 P.M. the same day he was suddenly seized with a severe rigor accompanied by vomiting and intense pain in the head and back, intolerance of light and sound, and some congestion of the conjunctivæ. The temperature soon after the rigor was $103^{\circ} \mathrm{F}$; t the pains were of a very severe shooting character and were aggravated by the slightest movement and by percussion of the spine. At 3.30 P.M. he was ordered ten grains of phenacetin every two hours up to 9 P.M. The pain was slightly relieved, but the temperature still kept up, being $102.4^{\circ}$ at 9 P.M. and $103^{\circ}$ at 10 P.M. The phenacetin was then stopped and he was ordered ten grains of antikamnia erery two hours when awake. The pain was immediately relieved and the temperature subsided to an average of $101^{\circ}$ (taken about every two hours).

Dr. Savill saw the case in consultation with me on May 7th. The fundi oculorum were then normal except that the retinal veins were considerably congested. Tine patient still complained of headache; the head was markedly retracted, and there was rery evident tache 